\title{
A mutation in the H/ACA box of telomerase RNA component gene (TERC) in a young patient with myelodysplastic syndrome
}

Yasutaka Ueda ${ }^{{ }^{*}}$, Rodrigo T Calado ${ }^{2}$, Anna Norberg ${ }^{3}$, Sachiko Kajigaya ${ }^{1}$, Göran Roos ${ }^{4}$, Eva Hellstrom-Lindberg ${ }^{5}$ and Neal S Young ${ }^{1}$

\begin{abstract}
Background: Telomeres are repeated sequences (the hexanucleotide TTAGGG in vertebrates) located at chromosome ends of eukaryotes, protecting DNA from end joining or degradation. Telomeres become shorter with each cell cycle, but telomerase, a ribonucleoprotein complex, alleviates this attrition. The telomerase RNA component (TERC) is an essential element of telomerase, serving as a template for telomere elongation. The H/ACA domain of TERC is indispensable for telomere biogenesis. Mutations in the telomerase components allow accelerated telomere loss, resulting in various disease manifestations, including bone marrow failure. To date, this is the first detailed report of an $\mathrm{H}$-box mutation in TERC that is related to human disease.
\end{abstract}

Case presentation: A 26-year-old man with myelodysplastic syndrome (MDS) had very short telomeres. Sequencing identified a single heterozygous mutation in the $\mathrm{H}$ box of the patient's TERC gene. The same mutation was also present in his father and his son, demonstrating that it was germline in origin. The telomere length in the father's blood was shorter compared to age-matched healthy controls, while it was normal in the son and also in the sperm cells of the patient. In vitro experiments suggested that the mutation was responsible for the telomere shortening in the patient's leukocytes and contributed to the pathogenesis of bone marrow failure in our patient.

Conclusion: We analyzed a mutation (A377G) in the H box of TERC in a young MDS patient who had significantly short-for-age telomeres. As telomeres protect chromosomes from instability, it is highly plausible that this genetic lesion was responsible for the patient's hematological manifestations, including marrow failure and aneuploidy in the hematopoietic stem cell compartment.

Keywords: Myelodysplastic syndrome (MDS), Telomerase RNA component (TERC), H/ACA box, Southern blotting, Single Telomere Elongation Length Analysis (STELA), RNA fluorescence in situ hybridization (RNA FISH)

\section{Background}

Telomeres are composed of a highly conserved repetitive DNA sequence (TTAGGG) at the ends of eukaryotic chromosomes with associated proteins, collectively termed shelterin. Telomeres protect DNA from fusion with neighboring chromosomes or degradation by exonuclease (reviewed in [1]). In humans, telomeres are $9-15 \mathrm{~kb}$ in length, and 100-200 base pairs of telomeric sequence are lost in each cell replication [2]. The molecular basis of loss

\footnotetext{
* Correspondence: yueda.maro@gmail.com

${ }^{1}$ Hematology Branch, National Heart, Lung, and Blood Institute, National Institutes of Health, Bldg 10-CRC, Rm 3E-5216, 9000 Rockville Pike, Bethesda, MD 20892, USA

Full list of author information is available at the end of the article
}

is inability to fully replicate DNA of the lagging strand during replication (known as the end replication problem) [3]. When telomere length is critically short, cells enter replicative senescence or die [4]. Telomere shortening is alleviated by enzymatic activity of telomerase, a complex composed of telomerase reverse transcriptase (TERT), telomerase RNA component (TERC), and other proteins (reviewed in [1]). In most human somatic cells, telomerase activity is suppressed; however, telomerase is active in proliferating progenitor cells.

TERC is an RNA component transcribed by RNA polymerase II which serves as a cognate template for telomere synthesis. In contrast to the relatively conserved 
TERT, TERC's structure, size, and sequence are divergent among different species. Nonetheless, TERC's secondary structure is similar across a wide range of eukaryotes. The human TERC gene (451 nucleotides (nt)) consists of three major domains: the core, the CR4/CR5, and the H/ACA scaRNA domains (Figure 1) [5]. The H/ACA scaRNA domain has two characteristic sequences, termed the $\mathrm{H}$ and ACA boxes, which resemble domains in small nucleolar RNAs (snoRNAs). The H/ACA boxes of TERC are essential for telomere biogenesis. H/ACA proteins, including dyskerin, NOP10, NHP2, and GAR1, recognize H/ACA-box sequences [6-8] and recruit TERC into a unique subnuclear organelle called Cajal body, which is crucial for assembly of telomerase components [9]. Mutations

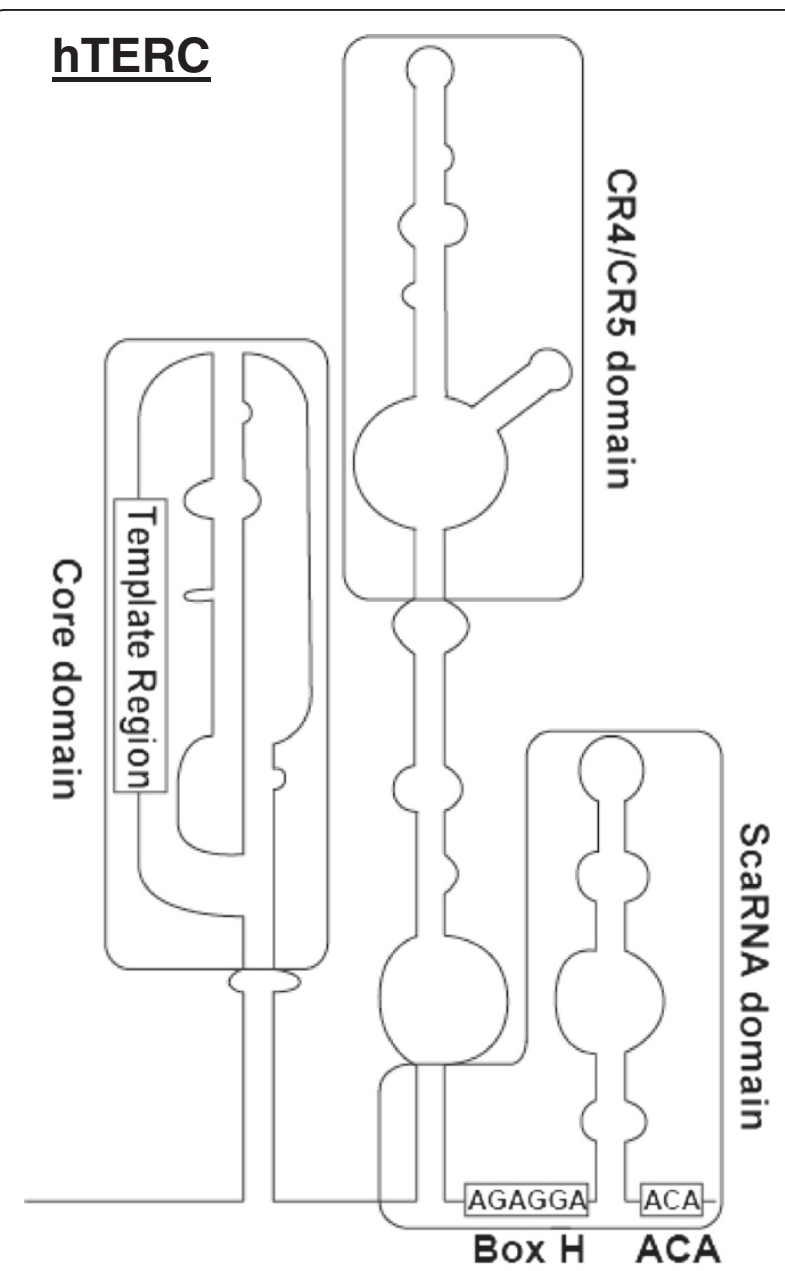

\section{wt : AGAGGA mut : AGAGGG}

Figure 1 The secondary structure of TERC showing the mutated nucleotide position identified in the patient. The $\mathrm{H}$ and ACA boxes and the scaRNA domain are highlighted. The $\mathrm{H}$ box sequences of wtTERC and mutTERC (A377G) are illustrated, with the mutated nucleotide $(A>G)$ shown as underlined. in the TERC gene as well as in other telomerase components cause accelerated telomere attrition, leading to disease: dyskeratosis congenita mainly in children [10-15], pulmonary fibrosis [16-18], liver cirrhosis [19], and bone marrow failure syndromes of adults (aplastic anemia, myelodysplastic syndromes (MDS), and others) [20-22].

Here, we report the association of an H-box mutation of TERC with human disease in a young man with bone marrow failure.

\section{Case presentation \\ Methods}

Patients, DNA extraction, and sequencing

A diagnosis of MDS was based on the World Health Organization (WHO) classification of myeloid neoplasms [23]. Having obtained written informed consent, peripheral blood samples were collected from our patient and his parents at the Karolinska University Hospital. Peripheral blood specimens of the patient's parents were separated into CD3-positive and -negative populations using a magneticactivated cell sorting (MACS) labeling system (Miltenyi Biotec, Bergishch Gladbach, Germany), according to the manufacturer's protocols.

Peripheral blood samples of the patient, his father, son and siblings were also obtained clinically at the Clinical Genetics Laboratory, Umeå University Hospital. A sample of the patient's sperm cells were collected before his bone marrow transplantation and analyzed for telomere length.

DNA was extracted from each separated cell population, peripheral blood specimens and the sperm sample using the QIAamp DNA Blood Mini kit or the QIAamp-96 spin blood kits (Qiagen, Hilden, Germany). DNA integrity was confirmed for all samples by agarose gel electrophoresis. All exons of the TERT and TERC genes were amplified by PCR using standard conditions and analyzed by direct sequencing using the BigDye Terminator v3.1 Cycle Sequencing kit on a ABI 3100 DNA Sequencer (Applied Biosystems, Grand Island, NY, USA), according to the manufacturer's instruction.

\section{Quantitative PCR ( $q P C R$ ) analysis of telomere length}

Telomere lengths of peripheral blood leukocytes in the patient and his parents were measured by qPCR as described by Cawthon [24,25], with several modifications [26], using the Qiagility robot and the Rotor-Gene Q (Qiagen). Telomere lengths of peripheral blood leukocytes in the MDS patient, his father, son and siblings, as well as of the patient's sperm cells were also measured by PCR at Umeå University as described previously [27]. Data of telomere lengths were combined with reference to the telomere length of the patient's peripheral blood leukocytes. 


\section{Single telomere elongation length analysis (STELA)}

STELA was performed as previously described [28]. Briefly, PCR-amplified DNA products were resolved by $0.7 \%$ LE agarose (Ambion, Carlsbad, CA, USA) gel electrophoresis, followed by detection with a probe against telomere repeats using the TeloTAGGG Telomere Length Assay kit (Roche Applied Science, Indianapolis, IN, USA), following the manufacturer's protocols. For each DNA specimen, five PCR reactions were performed in duplicate.

\section{Plasmid construction and telomeric repeat amplification protocol (TRAP) assay}

pcDNA3 TERC was constructed by inserting TERC sequence into pcDNA3 plasmid (Invitrogen, Carlsbad, CA, USA) at KpnI and EcoRI sites. A377G mutation was generated in pcDNA3 plasmid by using QuikChange Lightning Site-Directed Mutageneis Kit (Agilent Technologies, Santa Clara, CA, USA) according to the manufacturer's instructions. The mutation was confirmed by Sanger sequencing. The results of the TRAP and the RNA FISH experiments were confirmed with two different A377G mutant clones.

Telomerase-deficient WI 38 VA13 subline 2RA cells (VA13; ATCC, Manassas, VA, USA) were plated on six-well culture plates $\left(4 \times 10^{5}\right.$ cells/ well) and incubated for 24 hours. Either pcDNA3-wtTERC $(2 \mu \mathrm{g})$ or pcDNA3- mutTERC (2 $\mu g$ ) was cotransfected with pcDNA3-Flag-TERT $(2 \mu \mathrm{g})$ into the VA13 cells using X-tremeGENE HP DNA Transfection Reagent (12 $\mu \mathrm{l}$, Roche Applied Science). After 48 hours, transfected cells were washed with cold PBS, and directly lysed with CHAPS buffer (EMD Millipore, Billerica, MA, USA) in the wells on ice. Protein concentration was measured with the BCA Protein Assay kit (Thermo Fisher Scientific Inc., Rockford, IL, USA), and telomerase activity was measured by the fluorescence-based TRAP assay using the TRAPeze $^{\oplus}$ XL Telomerase Detection kit (EMD Millipore, Billerica, MA, USA), according to the manufacturer's instructions.

\section{RNA fluorescence in situ hybridization (RNA FISH)}

pcDNA3-wtTERC or pcDNA3-mutTERC was cotransfected with pcDNA3-Flag-TERT into VA13 cells as described above, and cells were subjected to RNA FISH 48 hours after transfection as described elsewhere [29,30]. As the mutation is located at nt 377 of TERC, we used a mixture of three probes which do not overlap the mutation site [30,31]. All probes were aminoallylT-modified deoxyoligonucleotides synthesized by Integrated DNA Technologies (Coralville, IA, USA).

Probe 1) $5^{\prime}$-T*GCGCGCGGGGAGCAAAAGCACGG

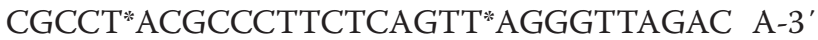
(complementary to TERC nt 43-96); Probe 2) 5' - GCT*G ACATTTTT*TGTTTGCTCT*AGAATGAACGGT*GGA A GGCGGCA GG CCGAGGCT*T-3' (complementary to
TERC nt 128-189); Probe 3) 5' -AT*GTGTGAGCCGAG T*CCTGGGTGCACGT*CCCACAGCTCAGGGAAT*CG CGCCGCGCT*C-3' (complementary to TERC nt 393-449). Aminoallyl-modified thymidines are indicated by $\mathrm{T}^{*}$. The aminoallyl-modified thymidines in the probes were chemically conjugated with $\mathrm{Cy} 3$ fluorophore (Cy3 monofunctional reactive dye; Amersham Pharmacia, Piscataway, NJ, USA), and the labeling efficiency was tested with Nanodrop 1000 (Thermo Scientific, Wilmington, DE, USA). Human p80-Coilin or dyskerin was detected with a mouse monoclonal anti-Coilin antibody (1:500 dilution; (Pdelta) ab11822, abcam, Cambridge, MA, USA) or a rabbit polyclonal anti-dyskerin antibody (1:50 dilution; (H-300) sc48794, Santa Cruz, Dallas, TX, USA), respectively. Slides were mounted in VECTASHIELD Mounting Medium with DAPI (Vector Laboratories, Burlingame, CA, USA). Images were acquired by confocal laser scanning microscopy with Zeiss LSM 780 confocal system (Carl Zeiss MicroImaging, NY, USA) at the Light Microscopy Core of NHLBI, NIH.

\section{Medical history}

The patient, born in 1983, was diagnosed with idiopathic thrombocytopenic purpura (ITP) in 1994, but no clinical follow-up was performed. In 2007, he was diagnosed with hypoplastic MDS with platelets $25 \times 10^{9} /$ l. Cytogenetic analysis in 2008 showed a partial trisomy 1q with 46,XY,der (13)t $(1 ; 13)(q 11 ; p 13)$ in 11 of 25 metaphase cells. In 2009, the patient was referred to the Karolinska University Hospital with pancytopenia showing leukocytes $2.0 \times 10^{9} / \mathrm{l}$, hemoglobin $10.0 \mathrm{~g} / \mathrm{dl}$, and platelets $20 \times 10^{9} / \mathrm{l}$. Absence of cytogenetic abnormalities and markedly reduced marrow cellularity on subsequent bone marrow biopsies (in 2009 and 2010) resulted in revision of the diagnosis from MDS to aplastic anemia (AA). The patient became transfusion-dependent (red blood cells and platelets) and susceptible to infection due to severe neutropenia (leukocyte $<0.2 \times 10^{9} / \mathrm{l}$ ). He underwent bone marrow transplantation in 2012, but died of Epstein-Barr virusassociated B-cell lymphoma in the same year. The patient's parents and two younger siblings were healthy, but the paternal grandmother had died with bone marrow hypoplasia at age 59. The grandmother's sister died of pneumonia at age 11, and her father died of pneumonia at age 50 (Figure $2 \mathrm{~B}$ ).

\section{Molecular analysis}

DNA samples of the patient and his parents were sent to the National Heart, Lung and Blood Institute for analysis in 2011. Since we suspected that the pedigree carried a genetic mutation in a telomerase-associated gene, we examined telomere content by qPCR. The telomere length of white blood cells in the patient was extremely short as compared to age-matched healthy controls (Figure 2A). Analysis of 
(A)

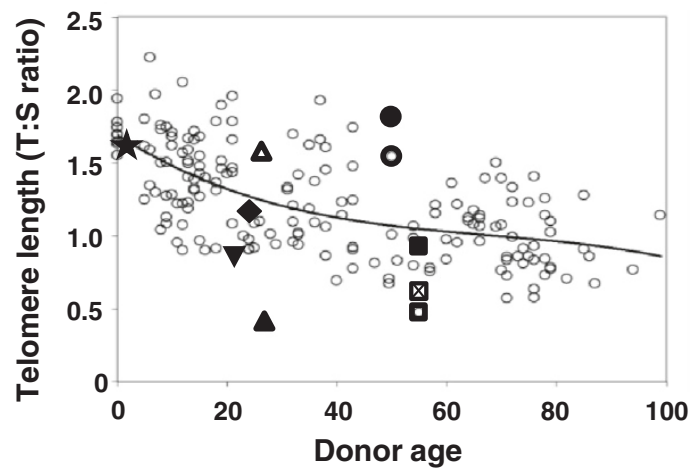

(B)

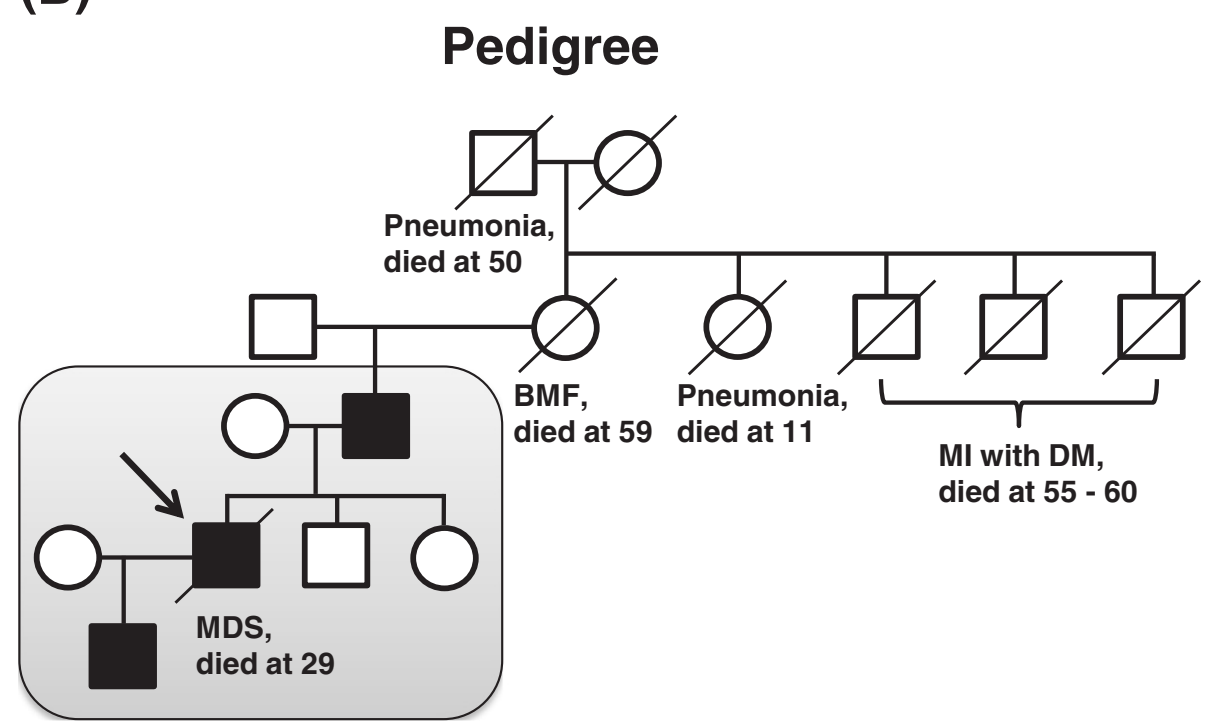

Figure 2 Familial analysis of telomere length and disease manifestations. A. The average telomere length in the patient was significantly short compared to age-matched healthy controls. Telomere length (TL) was measured by qPCR and calculated as the telomere to single copy gene ratio (T:S ratio). The figure illustrates the standard curve for age-related telomere length shortening in healthy donors (small open circles). The TL of each specimen is shown as follows; the patient peripheral blood (PB), $\mathbf{\Delta}$; the patient's sperm, $\triangle$; PB of the patient's son, $\boldsymbol{\star}$; whole PB of the patient's father, $\bigotimes, C D 3$-negative PB of the patient's father, $\mathbf{\square}$; CD3-positive PB of the patient's father, $\square ;$ CD3-negative PB of the patient's mother, $\bullet$; CD3-positive PB of the patient's mother, o; and PB of the patient's siblings, sister $\boldsymbol{\nabla}$ and brother $\bullet$. B. Pedigree analysis. The family members within the shaded box were tested for the A377G TERC mutation and telomere length. The proband is indicated with an arrow. Filled symbols represent individuals carrying the A377G mutation, whereas open symbols are individuals with no mutation. Squares; males, and circles; females. BMF, bone marrow failure; MI, myocardial infarction; DM, diabetes mellitus; and MDS, myelodysplastic syndrome.

the relatives showed that the father had shorter telomere length than the controls, whereas both siblings and the patient's son showed normal-for-age telomere content.

To further examine telomere attrition in our patient, we employed the PCR-based technique STELA for measurement of single telomere lengths in a chromosome-specific manner. Southern blot visualization of STELA was obtained by using telomere-specific probes (Figure 3). Telomere lengths in $12 q$ and especially in XpYp were widely distributed with many short telomeres, whereas they were less heterogeneous in $17 \mathrm{p}$ (Figure 3 ). Telomere lengths in controls were well-maintained within a defined length range, compared to those of the patient. 17p telomere length in controls also displayed low variation (data not shown); 17p telomere length distributions have been reported to be less heterogeneous compared to other chromosomes in fibroblasts and peripheral blood leukocytes [32].

As the patient had very short telomeres, we sequenced all exons of the TERT and TERC genes. Only a single heterozygous mutation at nt 377 (A377G) of TERC was identified within the $\mathrm{H}$ box of the H/ACA scaRNA 


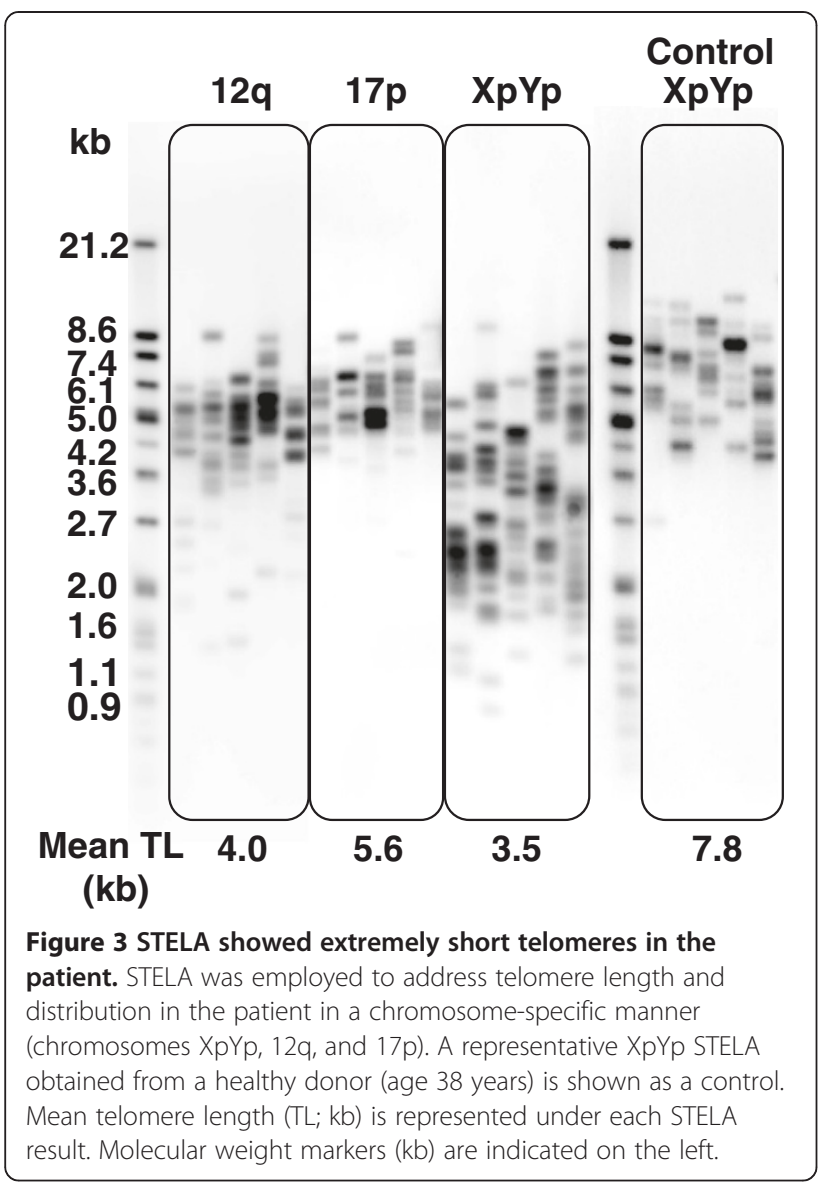

domain (Figure 1). The same mutation was also found in the patient's father, both in CD3-positive and CD3-negative populations, but not in the mother, suggesting origin in the paternal germline. An extended family analysis also identified the A377G mutation in the patient's son, whereas the patient's two healthy siblings did not have the mutation. A paternal influence has been reported on telomere length of offspring [33,34], but the patient's son showed normal telomere length despite his A377G mutation (Figure 2A). To clarify the inheritance of short telomere length of the patient, we examined the telomere length of the patient's sperm cells: surprisingly, the telomere length of the sperm cells was much longer compared to the patients' leukocytes (Figure 2A).

To address whether the TERC A377G mutation was responsible for telomere shortening in the patient, telomerase activity was measured by a TRAP assay, in which pcDNA3-wtTERC or mutTERC was co-transfected with pcDNA3-Flag-TERT into telomerase-deficient VA13 cells. Telomerase activity was significantly reduced (70 - 90\%) in VA13 cells that had been transfected with the mutant TERC plasmid (Figure 4).

Mutations in the H/ACA boxes of the TERC gene have been reported to be important for TERC to assemble with

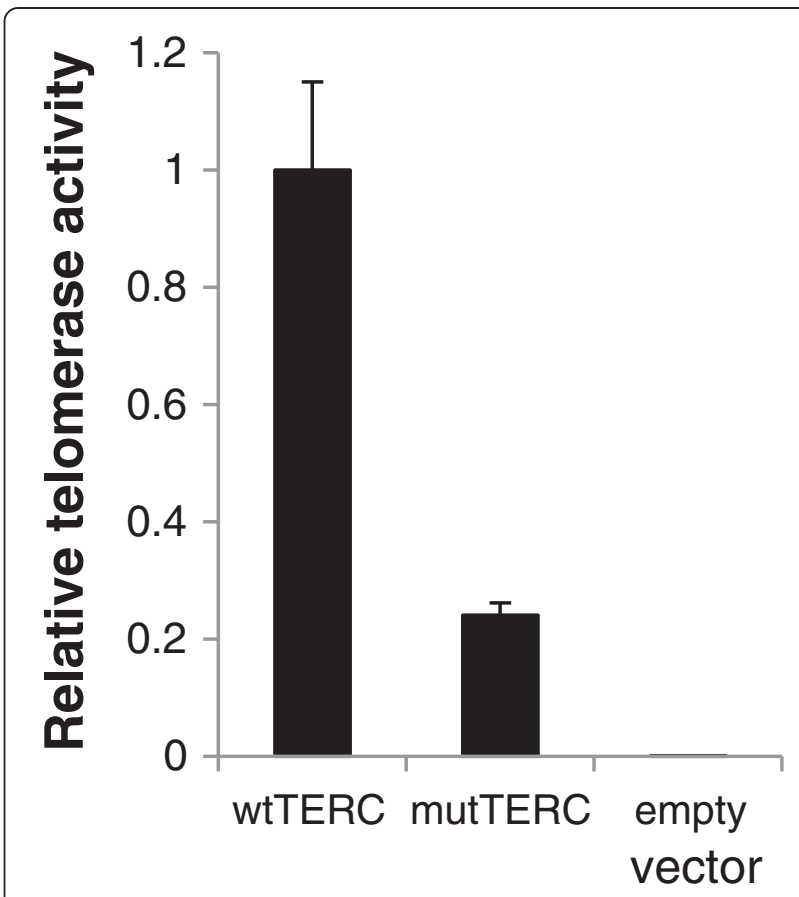

Figure 4 TRAP assay showed significantly low telomerase activity in the mutTERC (A377G). VA13 cells were co-transfected with either PCDNA3-wtTERC or pCDNA3-mutTERC together with pCDNA3-Flag-TERT, followed by telomerase activity measurement. Results were calculated as a relative activity compared to values obtained from pcDNA3-wtTERC and pcDNA3-Flag-TERT. Bars denote standard deviations. A representative result is shown here.

H/ACA proteins including dyskerin [35]. To test the hypothesis that the TERC A377G mutation might cause decreased telomerase activity through impaired interaction of TERC with H/ACA proteins or mislocalization of TERC in the nucleus, we performed RNA FISH using VA13 cells transiently transfected with pcDNA3-wtTERC / mutTERC. mutTERC did not colocalize with Cajal body marker coilin (Figure 5A and B). Furthermore, mutTERC did not colocalize with dyskerin (Figure 5C and D).

\section{Discussion}

In this study, we have identified a mutation A377G (AGAGGA $\rightarrow$ AGAGGG) in the $\mathrm{H}$ box of TERC in a young patient with bone marrow failure. The patient displayed short telomeres and significantly reduced telomerase activity in vitro in the TRAP assay, suggesting that the $\mathrm{H}$ box of TERC is crucial for telomere biogenesis in humans. Analysis of the pedigree showed that the mutation was germline. The father had no clinical symptoms, by the age of 58 , although he carried the mutation, consistent with previous reports which have observed variable penetrance of disease manifestations in patients carrying TERC mutations [21,36]. The patient's son carrying the mutation had also not shown clinical 

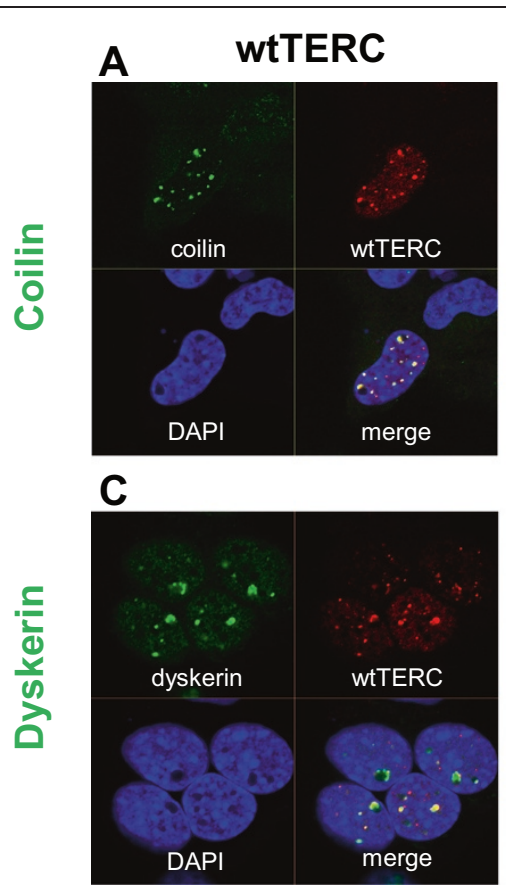

B mutTERC

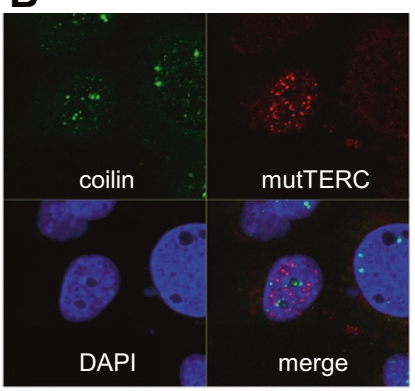

D

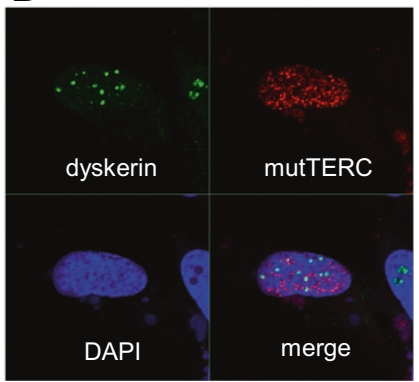

Figure 5 mutTERC did not colocalize with dyskerin or Cajal bodies. Telomerase-defective VA13 cells were transfected with either pcDNA3-wtTERC ( $\mathbf{A}$ and $\mathbf{C}$ ) or pcDNA3-mutTERC (B and $\mathbf{D}$ ) together with pcDNA3-Flag-TERT and subjected to RNA FISH combined with immunofluorescence. wtTERC or mutTERC was labeled with Cy3-conjugated probes (red, A-D), Cajal bodies and dyskerin were stained with anti-Coilin antibody (green, $\mathbf{A}$ and $\mathbf{B}$ ) and anti-dyskerin antibody (green, $\mathbf{C}$ and $\mathbf{D}$ ), respectively. Nucleus was stained with DAPI (blue, A-D).

symptoms and he had normal telomere length at age one year. However, close follow-up of the boy in the future would be necessary.

The A377G TERC mutation was previously reported in an aplastic anemia patient, but no functional assay of the mutation was performed [37]. The $\mathrm{H}$ box is extensively conserved among snoRNAs and scaRNAs in eukaryotes, sharing the consensus sequence "ANANNA (A: adenine, $\mathrm{N}$ : any nucleotide)". Microinjection experiments in Xenopus oocytes have shown that all three conserved adenine nucloetides of the $\mathrm{H}$ box are essential for nucleolar localization of snoRNA U64 [38]. A human TERC mutant, which was created by replacement of all adenines with uracil in the conserved $\mathrm{H}$ box residues (AGAGGA $\rightarrow$ UGUGGU), was undetectable in transiently transfected 293 cells using polyacrylamide gel electrophoresis [6]. Another H-box mutant (A372U) was subjected to in vitro RNA synthesis and immunoprecipitation experiments, showing severely impaired ribonucleoprotein (RNP) formation and a critical role of the $\mathrm{H}$ box for assembly of hTERC with H/ACA proteins [35]. These studies demonstrate that integrity of the $\mathrm{H}$ box is essential for hTERC stability, intracellular trafficking, and assembly of hTERC with H/ACA proteins.

In our study, RNA FISH experiments showed that mutTERC did not accumulate in Cajal bodies, and did not colocalize with dyskerin. Mislocalization of mutTERC with dyskerin is consistent with the previous report [35]. As dyskerin has been reported to be necessary for the active telomerase enzyme complex [39], lack of association of mutTERC with dyskerin might have caused shorterfor-age telomere length in our patient. mutTERC did not accumulate in Cajal bodies in the absence of CAB box mutations. Lack of pre-RNP formation might have caused this mislocalization. Ideally, telomerase activity should have been tested on the patient's samples, but these were not available.

Of interest, telomere content of the patient's sperm cells was much greater compared to his leukocytes. Sperm telomere length has been reported to correlate with that of white blood cells in the same individual [40], but sperm telomere length also has been reported to increase with age [40-43]. The mechanism of elongation is not understood, but upregulation of $h T E R T$ is suggested to contribute [44-46]. Upregulation of hTERT might have overcome a decrease of telomerase activity due to the A377G TERC mutation in our patient. A decrease in telomerase activity with telomerase mutations leads to telomere shortening with clinical manifestations in the hematopoietic system, but might not occur during spermatogenesis. Disease anticipation has been reported in TERC RNA haploinsufficiency [36,47]. Azospermia was observed in one affected individual, suggesting that spermatogenesis was also affected by TERC deletion [47]. 
Our case suggests that severity of telomere shortening during spermatogenesis might be different depending on mutation sites of TERC. Further analysis of individuals with telomerase mutations is needed to examine to what extent telomere length maintenance in sperm and bone marrow differs.

\section{Conclusions}

The A377G mutation was identified in the $\mathrm{H}$ box of TERC in a young MDS patient with a chromosomal abnormality. As telomeres protect chromosomes from instability, it is highly plausible that this genetic lesion was responsible for the patient's hematological manifestations, including marrow failure and aneuploidy in the hematopoietic stem cell compartment.

\section{Consent}

The patient and his parents provided written informed consent for genetic testing, and publication of the results following the protocol approved by the institutional review board of the National Heart, Lung, and Blood Institute, protocol 04-H-0012 (www.ClinicalTrials.gov identifier: NCT00071045). Analyses of peripheral blood samples from the patient's son and siblings were performed clinically after informed consent. Sperm DNA was analyzed after approval by the Ethical Committee at Umeå University (\#2013/157-31).

\section{Abbreviations}

TERC: Telomerase RNA component; MDS: Myelodysplastic syndrome; TERT: Telomerase reverse transcriptase; TRAP: Telomeric repeat amplification protocol; STELA: Single telomere elongation length analysis; RNA FISH: RNA fluorescence in situ hybridization.

\section{Competing interests}

The authors declare that they have no competing interests.

\section{Authors' contributions}

YU and SK carried out the molecular genetic studies, designed the study, and drafted the manuscript. RTC carried out the sequencing analysis, qPCR analysis, and designed the study. AN and GR performed sequencing and qPCR analysis (see Methods) and drafted the manuscript. EHL performed DNA extraction and provided vital clinical samples and information. NSY coordinated and supervised the study. All the authors revised and approved the final version of the manuscript.

\section{Acknowledgements}

We are grateful to the patient and his parents for their participation in this research. We also thank Dr. Daniela Malide at the Light Microscopy Core of NHLBI for technical help. This research was supported by the Intramural Research Program of the NIH, the NHLBI, and by the Swedish Cancer Research Foundation.

\section{Author details}

'Hematology Branch, National Heart, Lung, and Blood Institute, National Institutes of Health, Bldg 10-CRC, Rm 3E-5216, 9000 Rockville Pike, Bethesda, MD 20892, USA. ²Department of Internal Medicine, University of São Paulo at Ribeirão Preto Medical School, Ribeirão Preto, São Paulo, Brazil. ${ }^{3}$ Department of Medical Biosciences, Medical and Clinical Genetics, Umeå University, Umeå, Sweden. ${ }^{4}$ Department of Medical Biosciences, Pathology, Umeå University, Umeå, Sweden. ${ }^{5}$ Karolinska University Hospital and Karolinska Institute, Stockholm, Sweden.
Received: 31 October 2013 Accepted: 12 June 2014

Published: 19 June 2014

\section{References}

1. Blackburn EH: Telomeres and telomerase: the means to the end (Nobel lecture). Angew Chem Int Ed Engl 2010, 49(41):7405-7421.

2. O'Sullivan RJ, Karlseder J: Telomeres: protecting chromosomes against genome instability. Nat Rev Mol Cell Biol 2010, 11(3):171-181.

3. Watson JD: Origin of concatemeric T7 DNA. Nat New Biol 1972 239(94):197-201.

4. Harley $C B$, Futcher $A B$, Greider CW: Telomeres shorten during ageing of human fibroblasts. Nature 1990, 345(6274):458-460.

5. Zhang Q, Kim NK, Feigon J: Architecture of human telomerase RNA. Proc Natl Acad Sci U S A 2011, 108(51):20325-20332.

6. Mitchell JR, Cheng J, Collins K: A box H/ACA small nucleolar RNA-like domain at the human telomerase RNA 3' end. Mol Cell Biol 1999, 19(1):567-576.

7. Vulliamy TJ, Marrone A, Knight SW, Walne A, Mason PJ, Dokal I: Mutations in dyskeratosis congenita: their impact on telomere length and the diversity of clinical presentation. Blood 2006, 107(7):2680-2685.

8. Li H: Unveiling substrate RNA binding to H/ACA RNPs: one side fits all. Curr Opin Struct Biol 2008, 18(1):78-85.

9. Machyna M, Heyn P, Neugebauer KM: Cajal bodies: where form meets function. Wiley Interdiscip Rev RNA 2013, 4(1):17-34.

10. Heiss NS, Knight SW, Vulliamy TJ, Klauck SM, Wiemann S, Mason PJ, Poustka A, Dokal I: X-linked dyskeratosis congenita is caused by mutations in a highly conserved gene with putative nucleolar functions. Nat Genet 1998, 19(1):32-38.

11. Mitchell JR, Wood E, Collins K: A telomerase component is defective in the human disease dyskeratosis congenita. Nature 1999, 402(6761):551-555.

12. Vulliamy T, Marrone A, Goldman F, Dearlove A, Bessler M, Mason PJ, Dokal I: The RNA component of telomerase is mutated in autosomal dominant dyskeratosis congenita. Nature 2001, 413(6854):432-435.

13. Walne AJ, Vulliamy T, Marrone A, Beswick R, Kirwan M, Masunari Y, Al-Qurashi FH, Aljurf M, Dokal I: Genetic heterogeneity in autosomal recessive dyskeratosis congenita with one subtype due to mutations in the telomerase-associated protein NOP10. Hum Mol Genet 2007, 16(13):1619-1629.

14. Vulliamy T, Beswick R, Kirwan M, Marrone A, Digweed M, Walne A, Dokal I: Mutations in the telomerase component NHP2 cause the premature ageing syndrome dyskeratosis congenita. Proc Natl Acad Sci U S A 2008, 105(23):8073-8078.

15. Savage SA, Giri N, Baerlocher GM, Orr N, Lansdorp PM, Alter BP: TINF2, a component of the shelterin telomere protection complex, is mutated in dyskeratosis congenita. Am J Hum Genet 2008, 82(2):501-509.

16. Armanios MY, Chen JJ, Cogan JD, Alder JK, Ingersoll RG, Markin C, Lawson WE, Xie M, Vulto I, Phillips JA 3rd, Lansdorp PM, Greider CW, Loyd JE: Telomerase mutations in families with idiopathic pulmonary fibrosis. New Engl J Med 2007, 356(13):1317-1326

17. Tsakiri KD, Cronkhite JT, Kuan PJ, Xing C, Raghu G, Weissler JC, Rosenblatt RL, Shay JW, Garcia CK: Adult-onset pulmonary fibrosis caused by mutations in telomerase. Proc Natl Acad Sci U S A 2007, 104(18):7552-7557.

18. Mushiroda T, Wattanapokayakit S, Takahashi A, Nukiwa T, Kudoh S, Ogura T, Taniguchi H, Kubo M, Kamatani N, Nakamura Y: A genome-wide association study identifies an association of a common variant in TERT with susceptibility to idiopathic pulmonary fibrosis. J Med Genet 2008, 45(10):654-656.

19. Calado RT, Regal JA, Kleiner DE, Schrump DS, Peterson NR, Pons V, Chanock SJ, Lansdorp PM, Young NS: A spectrum of severe familial liver disorders associate with telomerase mutations. PloS one 2009, 4(11):e7926.

20. Yamaguchi H, Baerlocher GM, Lansdorp PM, Chanock SJ, Nunez O, Sloand E, Young NS: Mutations of the human telomerase RNA gene (TERC) in aplastic anemia and myelodysplastic syndrome. Blood 2003, 102(3):916-918.

21. Fogarty PF, Yamaguchi H, Wiestner A, Baerlocher GM, Sloand E, Zeng WS, Read EJ, Lansdorp PM, Young NS: Late presentation of dyskeratosis congenita as apparently acquired aplastic anaemia due to mutations in telomerase RNA. Lancet 2003, 362(9396):1628-1630.

22. Yamaguchi H, Calado RT, Ly H, Kajigaya S, Baerlocher GM, Chanock SJ, Lansdorp PM, Young NS: Mutations in TERT, the gene for telomerase reverse transcriptase, in aplastic anemia. New Engl J Med 2005, 352(14):1413-1424. 
23. Vardiman JW, Harris NL, Brunning RD: The World Health Organization (WHO) classification of the myeloid neoplasms. Blood 2002, 100(7):2292-2302.

24. Cawthon RM: Telomere measurement by quantitative PCR. Nucleic Acids Res 2002, 30(10):e47.

25. Cawthon RM: Telomere length measurement by a novel monochrome multiplex quantitative PCR method. Nucleic Acids Res 2009, 37(3):e21.

26. Winkler T, Hong SG, Decker JE, Morgan MJ, Wu C, Hughes WM, Yang Y, Wangsa D, Padilla-Nash HM, Ried T, Young NS, Dunbar CE, Calado RT: Defective telomere elongation and hematopoiesis from telomerase-mutant aplastic anemia iPSCs. J Clin Invest 2013, 123(5):1952-1963.

27. Nordfjall K, Osterman P, Melander O, Nilsson P, Roos G: hTERT (-1327)T/C polymorphism is not associated with age-related telomere attrition in peripheral blood. Biochem Biophys Res Commun 2007, 358(1):215-218.

28. Baird DM, Rowson J, Wynford-Thomas D, Kipling D: Extensive allelic variation and ultrashort telomeres in senescent human cells. Nat Genet 2003, 33(2):203-207.

29. Zenklusen $\mathrm{D}$, Singer $\mathrm{RH}$ : Analyzing mRNA expression using single mRNA resolution fluorescent in situ hybridization. Methods Enzymol 2010, 470:641-659.

30. Abreu E, Terns RM, Terns MP: Visualization of human telomerase localization by fluorescence microscopy techniques. Methods Mol Biol 2011, 735:125-137

31. Zhu Y, Tomlinson RL, Lukowiak AA, Terns RM, Terns MP: Telomerase RNA accumulates in Cajal bodies in human cancer cells. Mol Biol Cell 2004, 15(1):81-90.

32. Britt-Compton B, Rowson J, Locke M, Mackenzie I, Kipling D, Baird DM: Structural stability and chromosome-specific telomere length is governed by cis-acting determinants in humans. Hum Mol Genet 2006 15(5):725-733

33. Nordfjall K, Larefalk A, Lindgren P, Holmberg D, Roos G: Telomere length and heredity: indications of paternal inheritance. Proc Natl Acad Sci U S A 2005, 102(45):16374-16378.

34. Nordfjall K, Svenson U, Norrback KF, Adolfsson R, Roos G: Large-scale parent-child comparison confirms a strong paternal influence on telomere length. Eur J Hum Genet 2010, 18(3):385-389.

35. Trahan C, Dragon F: Dyskeratosis congenita mutations in the H/ACA domain of human telomerase RNA affect its assembly into a pre-RNP. RNA 2009, 15(2):235-243.

36. Vulliamy T, Marrone A, Szydlo R, Walne A, Mason PJ, Dokal I: Disease anticipation is associated with progressive telomere shortening in families with dyskeratosis congenita due to mutations in TERC. Nat Genet 2004, 36(5):447-449

37. Vulliamy TJ, Kirwan MJ, Beswick R, Hossain U, Baqai C, Ratcliffe A, Marsh J, Walne A, Dokal I: Differences in disease severity but similar telomere lengths in genetic subgroups of patients with telomerase and shelterin mutations. PloS One 2011, 6(9):e24383.

38. Lukowiak AA, Narayanan A, Li ZH, Terns RM, Terns MP: The snoRNA domain of vertebrate telomerase RNA functions to localize the RNA within the nucleus. RNA 2001, 7(12):1833-1844.

39. Cohen SB, Graham ME, Lovrecz GO, Bache N, Robinson PJ, Reddel RR: Protein composition of catalytically active human telomerase from immortal cells. Science 2007, 315(5820):1850-1853.

40. Aston Kl, Hunt SC, Susser E, Kimura M, Factor-Litvak P, Carrell D, Aviv A Divergence of sperm and leukocyte age-dependent telomere dynamics: implications for male-driven evolution of telomere length in humans. Mol Hum Reprod 2012, 18(11):517-522.

41. Allsopp RC, Vaziri H, Patterson C, Goldstein S, Younglai EV, Futcher AB, Greider CW, Harley CB: Telomere length predicts replicative capacity of human fibroblasts. Proc Natl Acad Sci U S A 1992, 89(21):10114-10118.

42. Baird DM, Britt-Compton B, Rowson J, Amso NN, Gregory L, Kipling D: Telomere instability in the male germline. Hum Mol Genet 2006, 15(1):45-51.

43. Kimura $M$, Cherkas LF, Kato BS, Demissie S, Hjelmborg JB, Brimacombe M, Cupples A, Hunkin JL, Gardner JP, Lu X, Cao X, Sastrasinh M, Province MA, Hunt SC, Christensen K, Levy D, Spector TD, Aviv A: Offspring's leukocyte telomere length, paternal age, and telomere elongation in sperm. PLoS Genet 2008, 4(2):e37.

44. Wright WE, Piatyszek MA, Rainey WE, Byrd W, Shay JW: Telomerase activity in human germline and embryonic tissues and cells. Dev Genet 1996, 18(2):173-179.

45. Zalenskaya IA, Zalensky AO: Telomeres in mammalian male germline cells. Int Rev Cytol 2002, 218:37-67.
46. Riou L, Bastos H, Lassalle B, Coureuil M, Testart J, Boussin FD, Allemand I, Fouchet $P$ : The telomerase activity of adult mouse testis resides in the spermatogonial alpha6-integrin-positive side population enriched in germinal stem cells. Endocrinology 2005, 146(9):3926-3932.

47. Goldman F, Bouarich R, Kulkarni S, Freeman S, Du HY, Harrington L, Mason PJ, Londono-Vallejo A, Bessler M: The effect of TERC haploinsufficiency on the inheritance of telomere length. Proc Natl Acad Sci U S A 2005, 102(47):17119-17124

doi:10.1186/1471-2350-15-68

Cite this article as: Ueda et al:: A mutation in the H/ACA box of telomerase RNA component gene (TERC) in a young patient with myelodysplastic syndrome. BMC Medical Genetics 2014 15:68.

\section{Submit your next manuscript to BioMed Central and take full advantage of:}

- Convenient online submission

- Thorough peer review

- No space constraints or color figure charges

- Immediate publication on acceptance

- Inclusion in PubMed, CAS, Scopus and Google Scholar

- Research which is freely available for redistribution

Submit your manuscript at www.biomedcentral.com/submit
C) Biomed Central 